\title{
Webinar dan akses ebook di masa pandemi Covid-19
}

\author{
Dhevi Enlivena Irene Restia Mahelingga \\ Balai Media dan Reproduksi LIPI \\ Gedung PDDI LIPI Lantai 6, Jln. Jend. Gatot Subroto 10, Jakarta 12710 \\ email: dhevlingga@gmail.com
}

\begin{abstract}
ABSTRAK
Pendahuluan. Wabah Corona atau pandemi Covid-19 membuka peluang untuk integrasi dan interaksi digital, tidak terkecuali dalam dunia penerbitan. LIPI Press sebagai penerbit ilmiah nasional menggunakan interaksi digital dalam bentuk webinar bedah buku sebagai salah satu bentuk layanan promosi dan diseminasi yang mendukung penerbitan hasil-hasil penelitian LIPI. Penelitian ini mengkaji pengaruh dari adanya webinar bedah buku terhadap jumlah pengakses ebook LIPI Press.
\end{abstract}

Metode penelitian. Penelitian mengukur jumlah akses ebook sebagai dampak dari adanya kegiatan webinar yang dilaksanakan LIPI Press.

Data analisis. Penelitian menggunakan role press manager untuk dapat mengakses salah satu fitur OMP yakni menampilkan statistik dari akses ebook, yakni sebelum, waktu promosi, dan saat kegiatan webinar berlangsung.

Hasil dan Pembahasan. Berdasarkan data pengakses ebook menunjukkan adanya kenaikan jumlah pengakses sejalan dengan kegiatan webinar, baik saat promosi, maupun pada saat kegiatan berlangsung. Hal menarik lainnya menunjukkan bahwa promosi webinar tidak hanya berdampak pada akses ebook yang akan dibahas, namun juga pada ebook lainnya.

Kesimpulan dan Saran. Promosi melalui webinar bedah buku dapat menjadi alternatif pilihan diseminasi karena tidak hanya berfungsi sebagai forum berbagi pengetahuan, tetapi juga sebagai promosi hasil terbitan. Kemajuan teknologi di bidang video conference juga bisa menekan biaya penyelenggaraan bedah buku sehingga pelaksanaannya tidak hanya efektif, tetapi juga efisien.

Kata kunci: Webinar; Ebook; Bedah Buku; Pandemi Covid-19

\section{A. PENDAHULUAN}

Wabah Corona atau pandemi Covid-19 membuka peluang untuk integrasi dan interaksi digital di bidang akademik. Penggunaan alat digital oleh para akademisi untuk konferensi, kuliah, dan rapat selama karantina wilayah membuktikan bahwa teknologi informasi yang tersedia saat ini dapat menggantikan banyak interaksi kerja fisik secara memadai. Format interaksi digital memungkinkan pertukaran dan kolaborasi antara individu dan kelompok kerja yang berjarak satu sama lain secara spasial. (Schwarz et al., 2020)

Tidak terkecuali dalam dunia penerbitan, LIPI Press sebagai penerbit ilmiah nasional menggunakan interaksi digital dalam bentuk webinar bedah buku di masa pandemi Covid-19. Kegiatan bedah buku LIPI Press tersebut merupakan salah satu bentuk layanan promosi dan diseminasi yang mendukung penerbitan hasil-hasil penelitian LIPI yang layak diketahui oleh publik. (Helmi et al., 2019) Bedah buku menjadi ajang berbagi pengetahuan hasil-hasil riset penelitian yang dikemas dalam bentuk buku ilmiah. Melalui kegiatan ini diharapkan masyarakat dapat mengetahui dan merasakan kontribusi hasil penelitian LIPI. 
Kegiatan bedah buku menggunakan interaksi digital seperti webinar tentunya sejalan dengan pergerakan penerbit yang mulai beradaptasi terhadap era digital di mana konten semakin banyak dikonsumsi dalam bentuk digital. (López et al., 2013) LIPI Press sendiri sejak awal 2020 sudah memfokuskan hasil terbitan hanya pada bentuk buku digital atau buku elektronik (ebook) yang dapat diakses secara bebas oleh publik. Hal tersebut didukung dengan implementasi LIPI Press menggunakan sistem penerbitan ilmiah daring berbasis Open Monograph Press (OMP). (Mahelingga, 2020b) Sistem berbasis teknologi informasi tersebut mengadaptasi proses bisnis penerbitan ilmiah konvensional menjadi berbasis interaksi digital secara daring yang sangat diperlukan pada masa pandemi Covid-19 dengan meminimalisasi kontak fisik.

Perubahan kebijakan LIPI Press yang beralih ke ebook dinilai tepat karena pada masa pandemi ini merupakan momentum bagi ebook untuk mendapatkan popularitasnya, karena keunggulannya dalam berbagi, pengiriman, dan penyebarluasan tanpa terkendala aspek fisik seperti buku cetak. Realitas tersebut senada dengan data penjualan buku digital yang dipublikasikan oleh penerbit Inggris pada tahun 2020 diprediksi mencapai titik tertinggi sepanjang sejarah. (Saputra, 2020) Sejumlah penerbit memperkirakan pencapaian ini terjadi karena adanya pandemi Covid-19.

Keduanya teknologi tersebut, baik ebook maupun webinar, merupakan bentuk format digital yang menurunkan biaya dan waktu yang umumnya dibutuhkan acara fisik seperti biaya akomodasi, dibandingkan untuk biaya hosting webinar kecil. (Schwarz et al., 2020) Namun demikian, muncul pertanyaan seberapa efektifkah peran webinar bedah buku sebagai media diseminasi, terutama dalam promosi ebook. Penelitian ini mengkaji pengaruh dari adanya webinar bedah buku terhadap jumlah pengakses ebook LIPI Press dan seberapa besar pengaruh webinar bedah buku terhadap persentase kenaikan jumlah pengakses ebook LIPI Press. Melalui penelitian ini diharapkan dapat memberikan gambaran tentang strategi promosi melalui webinar di masa pandemi Covid-19.

\section{B. TINJAUAN PUSTAKA}

\section{Webinar}

Webinar adalah presentasi akademis daring secara langsung, di mana pemirsa yang berpartisipasi dapat mengirimkan pertanyaan dan komentar. (Merriam-Webster, 2020b) Webinar memungkinkan peserta untuk melihat bagian dari perkuliahan atau seminar dalam siaran langsung melalui sistem konferensi video. Peserta terhubung pada perangkat lunak yang mendukung narasumber untuk berbagi dan mengirim dokumen, menggunakan papan gambar, membuat jajak pendapat, dan memungkinkan peserta untuk berkontribusi baik secara lisan maupun tertulis menggunakan papan obrolan. (Nagy \& Bernschütz, 2016)

Tujuan dari sistem webinar adalah untuk memastikan tampilan presentasi secara real-time serta melihatnya kembali secara retroaktif. Sistem webinar memberikan kesempatan untuk melihat kelas secara daring menggunakan sistem konferensi video sehingga memecahkan kesulitan peserta yang tidak dapat menghadiri presentasi secara langsung. (Nagy \& Bernschütz, 2016)

\section{Zoom}

Zoom adalah layanan konferensi video kolaboratif berbasis cloud yang menawarkan fitur termasuk rapat online, layanan perpesanan grup, dan perekaman sesi konferensi yang aman. (Zoom Video Communications Inc., 2016) Seperti platform serupa yakni Skype, Zoom menawarkan kemampuan untuk berkomunikasi secara real time dengan individu yang tersebar secara geografis melalui komputer, tablet, atau perangkat seluler. (Archibald et al., 2019) 
Namun, tidak seperti banyak teknologi Voice over Internet Protocol (VoIP) lainnya, Zoom memiliki sejumlah keunggulan tambahan yang meningkatkan kegunaannya. Kelebihan utama Zoom adalah kemampuannya untuk merekam dan menyimpan sesi dengan aman tanpa bantuan perangkat lunak pihak ketiga. Fitur ini sangat penting dalam penelitian yang memerlukan perlindungan data yang sangat sensitif. Fitur keamanan penting lainnya termasuk otentikasi khusus pengguna, enkripsi rapat secara real-time, dan kemampuan untuk mencadangkan rekaman ke jaringan server jarak jauh daring (cloud) atau disimpan di komputer lokal, yang kemudian dapat dibagikan dengan aman untuk tujuan kolaborasi. (Archibald et al., 2019)

\section{Ebook}

Ebook atau buku elektronik adalah buku yang disusun atau diubah ke dalam format digital untuk ditampilkan di layar komputer atau perangkat genggam. (Merriam-Webster, 2020a) Ebook pertama kali dikenal sejak peluncuran Proyek Gutenberg pada tahun 1971, upaya sukarela untuk membuat perpustakaan digital buku dan media budaya di domain publik. Ebook menawarkan beberapa keunggulan dibandingkan cetakan pendahulunya, seperti dapat dibeli, diunduh, dan dibaca langsung tanpa harus pergi ke toko buku atau perpustakaan. (OECD, 2012)

Ribuan ebook dapat menempati satu e-reader yang lebih kecil dan lebih ringan dari judul bersampul tradisional. Karya yang tidak dibatasi hak cipta dapat diunduh secara gratis. Produksi ebook tidak membutuhkan kertas atau tinta dan distribusinya membutuhkan usaha minimal. Ebook sering kali dapat dicadangkan di komputer atau cloud, membuatnya kebal terhadap kehilangan, pencurian, atau kerusakan. Teknologi terkini ebook mampu menampilkan gerakan, memperbesar teks, mengubah font, atau memanfaatkan text-to-speech untuk penyandang disabilitas. (OECD, 2012)

Namun dalam perkembangannya, ebook masih menempati ceruk kecil di industri perbukuan sebelum Amazon meluncurkan gawai ebook reader atau e-reader Kindle pada akhir tahun 2007. Kindle menawarkan pengalaman membaca yang nyaman, konektivitas nirkabel, dan akses ke inventaris buku Amazon. Selain itu, bisnis mapan Amazon yang menjual buku cetak secara daring memberinya akses siap pakai ke sejumlah besar pembeli buku sekaligus mempromosikan e-reader Kindle dan ebook. (Gilbert, 2015)

\section{Open Monograph Press (OMP)}

Open Monograph Press (OMP) adalah platform perangkat lunak sumber terbuka untuk mengelola alur kerja editorial yang diperlukan untuk meninjau monografi, bunga rampai, dan edisi akademik melalui tinjauan internal dan eksternal, pengeditan, pembuatan katalog, produksi dan publikasi. (Mahelingga, 2020a)

Sistem OMP mencakup proses penerbitan dan manajemen buku yang dapat dioperasikan oleh pengelola penerbitan secara fleksibel yang dapat diunduh secara gratis dan diinstal pada sebagian besar peladen web. OMP dirancang secara efisien untuk mengurangi waktu dan tenaga yang dibutuhkan untuk tugas-tugas substansial dan manajerial yang terkait dengan penerbitan buku sekaligus meningkatkan proses pencatatan dan efisiensi proses editorial. OMP dibangun untuk meningkatkan kualitas penerbitan ilmiah dan publik melalui sejumlah inovasi yang mencakup alur kerja yang jelas dan intuitif untuk setiap aspek pengiriman naskah, penelaahan, pengeditan, dan proses produksi. (Mahelingga, 2020a) 


\section{METODE PENELITIAN}

\section{Subjek Kajian}

Subjek kajian dibatasi pada kegiatan webinar bedah buku "Knowledge Sharing dan Bedah Buku Perempuan Kepala Daerah, Oligarki, dan Penanggulangan Kemiskinan Berperspektif Gender" yang diselenggarakan oleh LIPI Press secara daring menggunakan Zoom Webinar dan dilaksanakan pada Senin, 14 September 2020. Sementara itu, jumlah akses ebook dibatasi pada buku berjudul (1) Perempuan Kepala Daerah dan Penanggulangan Kemiskinan Berperspektif Gender di Indonesia dan (2) Perempuan Kepala Daerah dalam Jejaring Oligarki Lokal. Keduanya merupakan buku yang dibedah dalam webinar tersebut.

\section{Konseptualisasi Penelitian}

Penelitian mengukur jumlah akses ebook Perempuan Kepala Daerah dan Penanggulangan Kemiskinan Berperspektif Gender di Indonesia dan Perempuan Kepala Daerah dalam Jejaring Oligarki Lokal sebagai dampak dari adanya kegiatan webinar "Knowledge Sharing dan Bedah Buku Perempuan Kepala Daerah, Oligarki, dan Penanggulangan Kemiskinan Berperspektif Gender". Pengukuran jumlah akses dibagi menjadi tiga periode, yakni sebelum webinar, saat promosi webinar, dan ketika webinar berlangsung. Secara garis besar dapat dilihat pada gambar 1. Hasil pengukuran kemudian dianalisis persentase kenaikannya dan dideskripsikan.

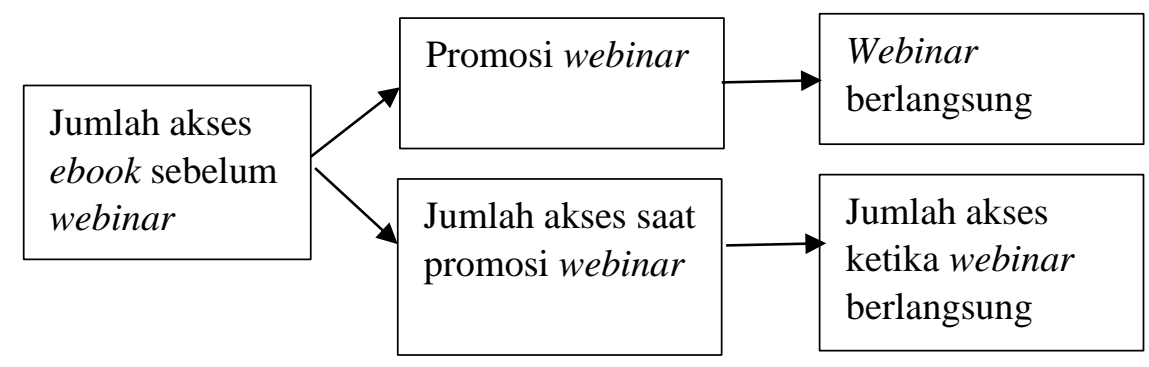

Gambar 1. Konseptualisasi Penelitian

\section{Pengumpulan Data}

Pengumpulan data primer dalam kajian ini didapat melalui sistem penerbitan LIPI Press yang berbasis OMP. Penelitian menggunakan role press manager untuk dapat mengakses salah satu fitur OMP yakni menampilkan statistik dari akses ebook. (Mahelingga, 2020b) Melalui fitur tersebut, data yang ingin diambil dapat diatur waktunya yakni sebelum, saat promosi, dan ketika webinar diselenggarakan. Data dapat diambil dalam bentuk tabel atau grafik garis untuk mengetahui efek dari webinar terhadap pergerakan akses ebook LIPI Press.

\section{HASIL DAN PEMBAHASAN}

\section{Bedah Buku melalui Webinar}

Webinar bedah buku bertajuk "Knowledge Sharing dan Bedah Buku Perempuan Kepala Daerah, Oligarki, dan Penanggulangan Kemiskinan Berperspektif Gender" dilaksanakan secara daring pada 14 September 2020 dan dihadiri oleh 102 peserta yang berasal dari berbagai kalangan, seperti dosen, peneliti, mahasiswa, praktisi, dan masyarakat umum. Kegiatan webinar ini mengupas kedua buku terkait perempuan kepala daerah yang diterbitkan oleh LIPI Press dan bertujuan untuk melihat sisi lain perempuan sebagai kepala 
pemerintahan di tingkat lokal, termasuk peran dan kinerja perempuan dalam merencanakan, menyusun, dan melaksanakan program kerja selama masa jabatan. (Dewi et al., 2020) (Dewi, 2017) Selain itu, acara ini juga dimaksudkan untuk mengedukasi publik agar semakin perhatian terhadap isu-isu yang menyangkut gender terutama peran perempuan dalam kontestasi kepala daerah menjelang ajang pemilihan kepala daerah pada 9 Desember 2020.

Kegiatan webinar bedah buku dilaksanakan secara daring menggunakan aplikasi Zoom Webinar dengan sistem pendaftaran. Promosi kegiatan webinar menggunakan media sosial Instagram, Facebook, dan Twitter serta selebaran elektronik yang disebar pada jejaring Whatsapp pada tujuh hari sebelum kegiatan berlangsung atau 7-13 September 2020. Melalui promosi tersebut, masyarakat diharapkan mendaftar sebagai peserta webinar melalui tautan yang disediakan untuk selanjutnya mendapatkan email ID dan passcode webinar pada H-1 kegiatan webinar. Alur waktu kegiatan dapat dilihat pada gambar 2.

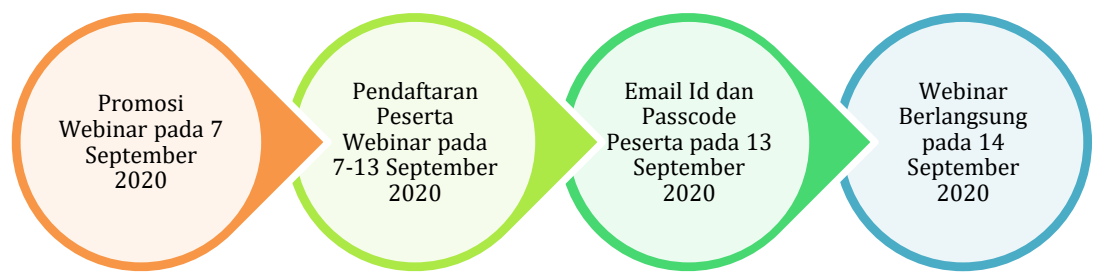

Gambar 2. Alur Waktu Penyelenggaraan Webinar

\section{Jumlah Akses Buku Elektronik}

Jumlah pengakses ebook LIPI Press dapat dipantau melalui fitur statistik dalam sistem penerbitan ilmiah daring OMP yang digunakan LIPI Press. Sebagai gambaran awal sebelum adanya kegiatan webinar dan promosi maka statistik diatur untuk memunculkan data akses selama tiga bulan sebelum kegiatan atau pada 6 Juni-6 September 2020. Berdasarkan data akses tersebut untuk ebook Perempuan Kepala Daerah dan Penanggulangan Kemiskinan Berperspektif Gender di Indonesia berada di posisi keempat dengan total akses 535 kali atau rata-rata diakses 5,8 kali dalam sehari. Sementara itu, untuk ebook Perempuan Kepala Daerah dalam Jejaring Oligarki Lokal berada di peringkat ke-80 dengan total akses hanya 46 kali atau rata-rata 0,5 kali diakses dalam sehari.

Secara lengkap data akses buku selama tiga bulan atau periode 6 Juni-6 September 2020 dapat dilihat pada Tabel 1.

Tabel 1. Jumlah Pengakses Ebook LIPI Press 6 Juni-6 September 2020

\begin{tabular}{|l|l|l|l|}
\hline $\begin{array}{l}\text { No } \\
\cdot\end{array}$ & Judul & $\begin{array}{l}\text { Total } \\
\text { Akses }\end{array}$ & $\begin{array}{l}\text { Rata- } \\
\text { rata }\end{array}$ \\
\hline 1 & $\begin{array}{l}\text { Prosiding Seminar Nasional Bahasa dan Sastra: Mengukuhkan Fungsi Bahasa dan } \\
\text { Sastra untuk Memperkuat Jati Diri Bangsa }\end{array}$ & 1200 & 12,9 \\
\hline 2 & Agama, Kultur (In)Toleransi, dan Dilema Minoritas di Indonesia & 994 & 10,7 \\
\hline 3 & Usada: Traditional Balinese Medicinal Plants & 725 & 7,8 \\
\hline 4 & $\begin{array}{l}\text { Perempuan Kepala Daerah dan Penanggulangan Kemiskinan Berperspektif Gender } \\
\text { di Indonesia }\end{array}$ & 535 & 5,8 \\
\hline 5 & $\begin{array}{l}\text { 101 Ikan Hias Air Tawar Nusantara } \\
\text { (2) }\end{array}$ & 432 & 4,6 \\
\hline 6 & Peta Sosial Politik Menjelang Pemilu Serentak 2019: Survei Pandangan Ahli & 369 & 4,0 \\
\hline
\end{tabular}




\begin{tabular}{|l|l|l|c|}
\hline 78 & Panduan Penelitian Bidang Ilmu Pengetahuan Alam bagi Pemula & 50 & 0,5 \\
\hline 79 & $\begin{array}{l}\text { Perpecahan dan Soliditas Partai Islam: Kasus PKB dan PKS di Dekade Pertama } \\
\text { Reformasi }\end{array}$ & 49 & 0,5 \\
\hline 80 & Perempuan Kepala Daerah dalam Jejaring Oligarki Lokal & 46 & 0,5 \\
\hline 81 & Standardisasi Produk Perikanan dan Olahannya dalam Penguatan Pasar Ekspor & 45 & 0,5 \\
\hline
\end{tabular}

Pada saat promosi kegiatan webinar mulai diunggah di media sosial, terjadi pergerakan pada jumlah akses kedua ebook yang akan dibedah. Selama 7-13 September 2020, ebook Perempuan Kepala Daerah dalam Jejaring Oligarki Lokal yang sebelumnya berada jauh di peringkat ke- 80 naik ke peringkat 4 dengan total akses 52 kali atau rata-rata diakses 7,4 kali dalam sehari. Jumlah tersebut meningkat $1.401,9 \%$ dari rata-rata jumlah akses pada 3 bulan sebelumnya. Sementara itu, ebook Perempuan Kepala Daerah dan Penanggulangan Kemiskinan Berperspektif Gender di Indonesia berada di peringkat ke-7 dengan total akses sebanyak 42 kali atau rata-rata diakses 6 kali dalam sehari. Jumlah tersebut juga meningkat 4,3\% dari rata-rata jumlah akses pada 3 bulan sebelumnya.

Secara keseluruhan sepuluh besar jumlah pengakses ebook LIPI Press pada 7-13 September 2020 dapat dilihat pada Tabel 2.

Tabel 2. Sepuluh Besar Jumlah Pengakses Ebook LIPI Press 7-13 September 2020

\begin{tabular}{|l|l|c|c|}
\hline No. & Judul & Total Akses & Rata-rata \\
\hline 1 & $\begin{array}{l}\text { Pengembangan Sensor Berbasis Teknologi Mikroelektronika untuk } \\
\text { Pemanfaatan Pencemaran Lingkungan }\end{array}$ & 245 & 35,0 \\
\hline 2 & $\begin{array}{l}\text { 101 Ikan Hias Air Tawar Nusantara } \\
3\end{array}$ & $\begin{array}{l}\text { Prosiding Seminar Nasional Bahasa dan Sastra: Mengukuhkan Fungsi Bahasa } \\
\text { dan Sastra untuk Memperkuat Jati Diri Bangsa }\end{array}$ & 66 \\
\hline 4 & $\begin{array}{l}\text { Perempuan Kepala Daerah dalam Jejaring Oligarki Lokal } \\
12,1\end{array}$ & 9,4 \\
\hline 5 & $\begin{array}{l}\text { Bahasa dan Budaya Dayak Sontas Bagi Persatuan Bangsa } \\
\text { Agama, Kultur (In)Toleransi, dan Dilema Minoritas di Indonesia }\end{array}$ & 52 \\
\hline 6 & $\begin{array}{l}\text { Perempuan Kepala Daerah dan Penanggulangan Kemiskinan Berperspektif } \\
\text { Gender di Indonesia }\end{array}$ & 42 & 6,7 \\
\hline 7 & $\begin{array}{l}\text { Pemanfaatan Data Satelit Radar untuk Wilayah Darat di Indonesia: Peluang dan } \\
\text { Tantangan }\end{array}$ & 39 & 6,0 \\
\hline 9 & $\begin{array}{l}\text { Teknologi Pengolahan Pakan Sapi Potong di Technopark Banyumulek, Nusa } \\
\text { Tenggara Barat }\end{array}$ & 38 & 5,6 \\
\hline 10 & $\begin{array}{l}\text { Kerentanan-Ketahanan Kawasan Landai Pesisir dan Pulau Kecil: Mitigasi dan } \\
\text { Adaptasinya }\end{array}$ & 37 & 5,4 \\
\hline
\end{tabular}

Pada saat hari-h kegiatan webinar berlangsung, yakni pada 14 September 2020 pergerakan jumlah pengakses ebook buku yang dibahas mengalami pelonjakan signifikan. Ebook Perempuan Kepala Daerah dan Penanggulangan Kemiskinan Berperspektif Gender di Indonesia pada hari tersebut berada di peringkat pertama dalam banyaknya akses dengan total akses 52 kali. Angka tersebut naik 766,7\% dari rata-rata akses selama 7 hari sejak promosi webinar diunggah ke media sosial. Sementara itu, ebook Perempuan Kepala Daerah dalam Jejaring Oligarki Lokal berada di peringkat kedua dengan 48 kali akses atau naik 546,2\% dari rata-rata akses 7 hari sebelumnya.

Secara keseluruhan sepuluh besar jumlah pengakses ebook LIPI Press pada 14 September 2020 dapat dilihat pada Tabel 3. 
Tabel 3. Sepuluh Besar Jumlah Pengakses Ebook LIPI Press 14 September 2020

\begin{tabular}{|c|c|c|}
\hline No. & Judul & Total Akses \\
\hline 1 & $\begin{array}{l}\text { Perempuan Kepala Daerah dan Penanggulangan Kemiskinan Berperspektif Gender di } \\
\text { Indonesia }\end{array}$ & 52 \\
\hline 2 & Perempuan Kepala Daerah dalam Jejaring Oligarki Lokal & 48 \\
\hline 3 & 101 Ikan Hias Air Tawar Nusantara & 20 \\
\hline 4 & $\begin{array}{l}\text { Prosiding Seminar Nasional Bahasa dan Sastra: Mengukuhkan Fungsi Bahasa dan Sastra } \\
\text { untuk Memperkuat Jati Diri Bangsa }\end{array}$ & 16 \\
\hline 5 & Kerentanan-Ketahanan Kawasan Landai Pesisir dan Pulau Kecil: Mitigasi dan Adaptasinya & 13 \\
\hline 6 & Usada: Traditional Balinese Medicinal Plants & 13 \\
\hline 7 & Garis Kemiskinan dan Kemiskinan Ecopos & 11 \\
\hline 8 & Ekspedisi Sumba & 10 \\
\hline 9 & $\begin{array}{l}\text { Tinjauan Kritis Ketahanan Sosial Masyarakat Miskin Perkotaan dan Perdesaan: Ruang } \\
\text { Sosial, Kebijakan, dan Pola Kerentanan Sosial }\end{array}$ & 10 \\
\hline 10 & Paradigma Ilmu Pengetahuan dan Penelitian Ilmu-ilmu Sosial dan Humaniora di Indonesia & 6 \\
\hline
\end{tabular}

Berdasarkan data pengakses kedua ebook yang dibahas pada Tabel 1, Tabel 2, maupun Tabel 3, menunjukkan adanya kenaikan jumlah pengakses sejalan dengan kegiatan webinar, baik saat promosi, maupun pada saat kegiatan berlangsung seperti terlihat pada Gambar 3. Hal menarik lainnya melihat grafik garis pada statistik OMP secara keseluruhan pada 7-14 September seperti tertuang pada Gambar 4. Terjadi kenaikan yang cukup tinggi pada saat promosi diunggah ke media sosial pada 7 September 2020, menunjukkan bahwa promosi webinar tidak hanya berdampak pada akses ebook yang dibahas dalam bedah buku, namun juga pada ebook lainnya. Grafik kemudian menurun pada hari setelahnya hingga titik terendah pada 11 September 2020. Namun kembali naik dan menuju puncak pada 14 September 2020 dengan ebook yang terbanyak diakses adalah ebook yang dibahas pada saat acara webinar berlangsung.

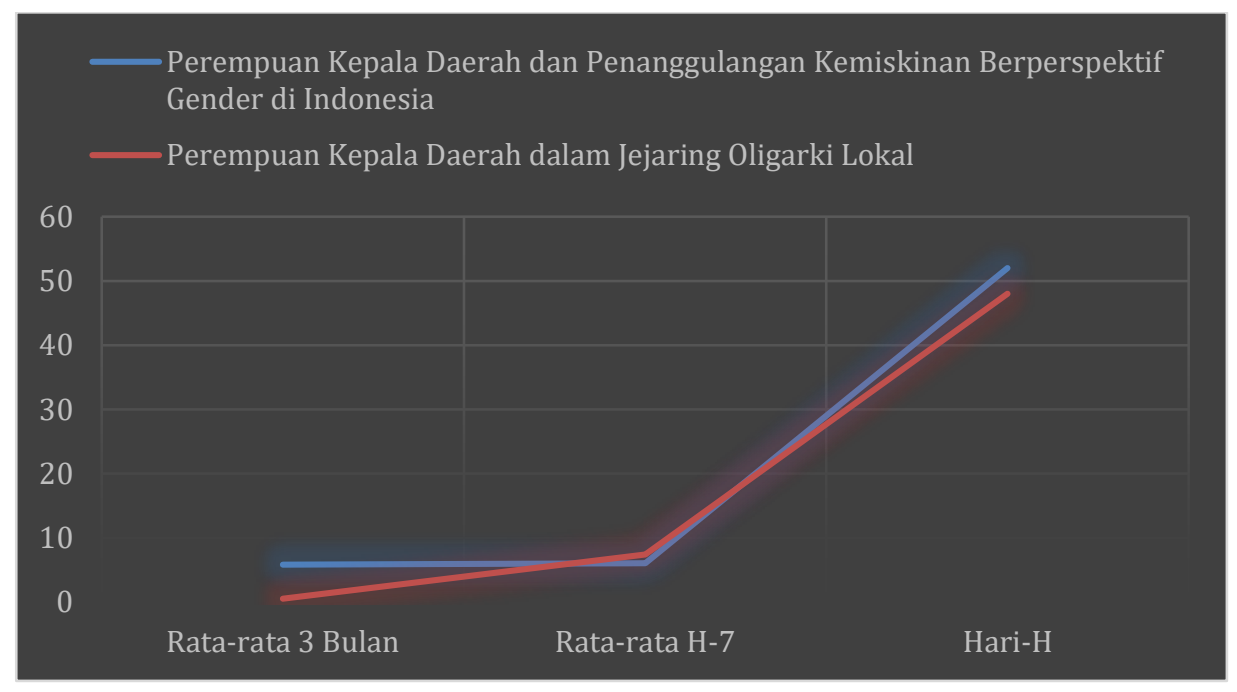

Gambar 3. Pergerakan akses ebook buku yang dibedah dalam webinar 


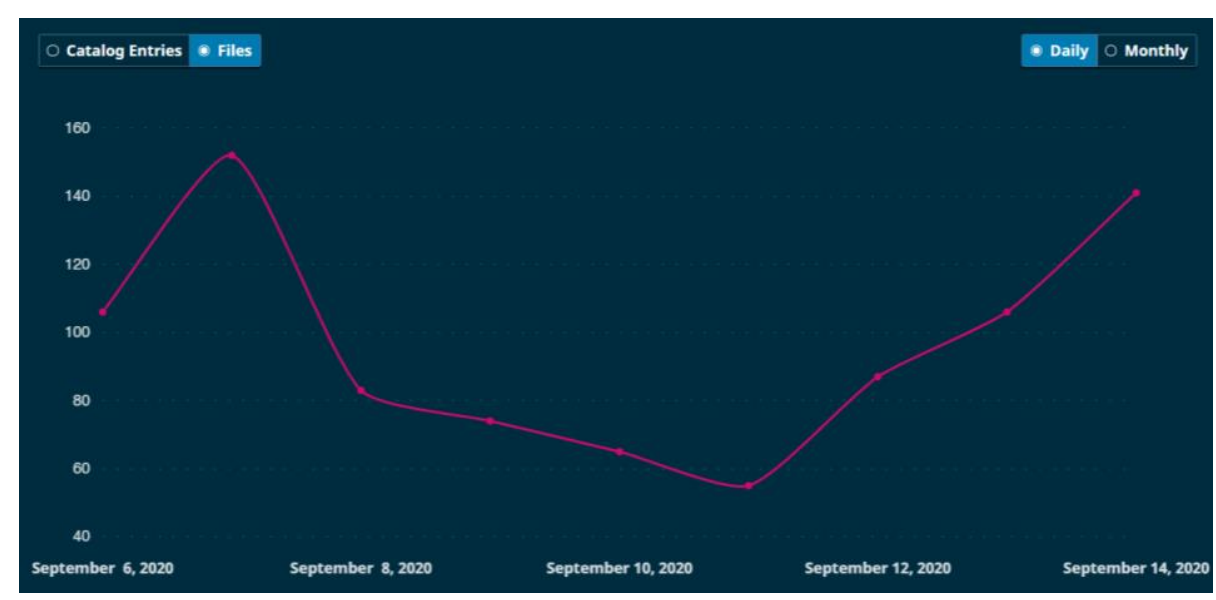

Gambar 4. Pergerakan akses ebook secara keseluruhan pada 7-14 September 2020

\section{E. KESIMPULAN}

Teknologi informasi merupakan bidang yang paling banyak berperan dalam segala aspek kehidupan di masa pandemi Covid-19 karena kemampuannya untuk mendukung interaksi digital dan meminimalisasi kontak fisik. Tidak terkecuali pada bidang penerbitan, popularitas ebook semakin melonjak dengan kemudahan akses dan perlengkapan pembaca ebook yang semakin mudah didapatkan. Di sisi lain teknologi video conference seperti Zoom dan Google Meet menjadi aplikasi yang diperlukan dalam penyelenggaraan kelas pendidikan, kuliah, konferensi, pelatihan, seminar, bimbingan teknis, dan forum berbagi pengetahuan lainnya, termasuk di dalamnya sebagai sebagai media promosi dan diseminasi.

Berdasarkan pembahasan di atas, dapat ditarik kesimpulan bahwa aspek promosi dari webinar bedah buku mampu memberikan dampak positif dalam peningkatan jumlah pengakses ebook yang dibedah, terlebih buku yang jarang diakses, di sisi lain juga turut mengangkat jumlah pengakses dari ebook lain. Promosi melalui webinar bedah buku dapat menjadi alternatif diseminasi karena tidak hanya berfungsi sebagai forum berbagi pengetahuan, tetapi juga sebagai promosi hasil terbitan. Kemajuan teknologi di bidang video conference juga bisa menekan biaya penyelenggaraan bedah buku sehingga pelaksanaannya tidak hanya efektif, tetapi juga efisien.

Kegiatan berbasis interaksi digital seperti webinar sangat cocok digunakan untuk media promosi produk digital juga, seperti ebook, terlebih pada masa pandemi Covid-19. Namun demikian, perlu adanya penelitian lanjutan, khususnya pada penerbit komersial untuk didapatkan gambaran dari aspek biaya yang dikeluarkan dengan profit yang didapatkan. Hal ini tidak dapat diukur dari LIPI Press sebagai penerbit plat merah yang tidak berorientasi pada keuntungan finansial.

\section{DAFTAR PUSTAKA}

Archibald, M. M., Ambagtsheer, R. C., Casey, M. G., \& Lawless, M. (2019). Using Zoom Videoconferencing for Qualitative Data Collection: Perceptions and Experiences of Researchers and Participants. International Journal of Qualitative Methods, 18, 1-8. https://doi.org/10.1177/1609406919874596

Dewi, K. H. (Ed.). (2017). Perempuan Kepala Daerah dalam Jejaring Oligarki Lokal. LIPI Press. 
Dewi, K. H., Aziz, N. L. L., \& Raharjo, S. N. I. (2020). Perempuan Kepala Daerah dan Penanggulangan Kemiskinan Berperspektif Gender di Indonesia. LIPI Press.

Gilbert, R. J. (2015). E-books: A Tale of digital disruption. Journal of Economic Perspectives, 29(3), 165-184. https://doi.org/10.1257/jep.29.3.165

Helmi, R. L., Safitri, M., Fazi, R., Mahelingga, D. E. . R., Suhendra, M. F., Hartiningsih, R. W., Indrasari, N. P., Kusuma, S. H., Taslima, R. H., Sasiwi, P., Dewi, S. P., Helmiawan, M., \& Puspita, A. D. (2019). Pedoman Penerbitan Buku LIPI Press. LIPI Press.

López, E. R., Places, Á. S., Lema, J. A. C., Fernández, O. P., \& Brisaboa, N. R. (2013). Towards commercial ebook production in small publishing houses. CSEDU 2013 - Proceedings of the 5th International Conference on Computer Supported Education, 116-121. https://doi.org/10.5220/0004384201160121

Mahelingga, D. E. I. R. (2020a). Panduan Praktis Pengiriman Naskah via Open Monograph Penjelasan Singkat OMP.

Mahelingga, D. E. I. R. (2020b). Penerbitan buku ilmiah daring berbasis open monograph press (OMP). Berkala Ilmu Perpustakaan, 16(2), 155-169. https://doi.org/10.22146/bip.v16i1.265

Merriam-Webster. (2020a). Definition of E-book by Merriam-Webster. https://www.merriamwebster.com/dictionary/e-book

Merriam-Webster. (2020b). Definition of Webinar by Merriam-Webster. https://www.merriamwebster.com/dictionary/webinar

Nagy, J. T., \& Bernschütz, M. (2016). The impact of webinar-webcast system on learning performance. Education and Information Technologies, 21(6), 1837-1845. https://doi.org/10.1007/s10639-015-9422-4

OECD. (2012). E-books: Developments and Policy Considerations. OECD Digital Economy Papers, 208. https://doi.org/10.1787/5k912zxg5svh-en OECD

Saputra, G. A. (2020). Penjualan E-Book dan Audio Book Meningkat Selama Pandemi. Media Indonesia. https://mediaindonesia.com/weekend/361901/penjualan-e-book-dan-audio-bookmeningkat-selama-pandemi

Schwarz, M., Scherrer, A., Hohmann, C., Heiberg, J., Brugger, A., \& Nuñez-Jimenez, A. (2020). COVID-19 and the academy: It is time for going digital. Energy Research and Social Science, 68(June), 0-2. https://doi.org/10.1016/j.erss.2020.101684

Zoom Video Communications Inc. (2016). Zoom Security Guide. Zoom Video Communications Inc. 